\title{
AS CONTRIBUIÇÕES DO PROGRAMA PFRH NA FORMAÇÃO DE UM TÉCNICO-CIDADÃO DO INSTITUTO FEDERAL DE EDUCAÇÃO, CIÊNCIA E TECNOLOGIA DO RIO GRANDE DO NORTE
}

\author{
Cristiane do Nascimento Fernandes, Aline Dayane Nunes da Silva, Hítalo Rhângelo de Sousa \\ cristiane_nascimento_fernandes@outlook.com; aliine_dayane@hotmail.com; hitalo.rhangelo@hotmail.com \\ Instituto Federal de Educação, Ciência e Tecnologia do Rio Grande do Norte - IFRN
}

DOI:10.15628/diálogos.2018.6638

Artigo submetido em dez/2017 e aceito em jun/2018

\section{RESUMO}

O presente trabalho possui o objetivo de apresentar como o Programa Petrobras de Formação de Recursos Humanos (PFRH) contribui para a melhoria da formação do técnico-cidadão egresso do Técnico em Edificações do Instituto Federal de Educação, Ciência e Tecnologia do Rio Grande do Norte (IFRN), possibilitando assim, a ampliação não só de seus horizontes na área acadêmica como também no mercado de trabalho, além de agir como ferramenta facilitadora para o profissional que opta por seguir a carreira de Engenheiro Civil ou Arquiteto. Nele serão apresentadas as principais atividades desenvolvidas no programa, bem como abordadas as oportunidades proporcionadas.

PALAVRAS-CHAVE: Ensino técnico, Técnico em Edificações, PFRH, IFRN, Educação.

\section{INTRODUÇÃO}

O progresso advindo das contribuições de Taylor, Ford e outros, permitiu que a indústria da Construção Civil tomasse avançados rumos, sobretudo, na economia global. Até os dias atuais, a gestão de operações ainda percorre um longo caminho de evoluções, especializações e experiências, na busca pela otimização dos processos construtivos.

No sentido de se aperfeiçoar as falhas existentes na execução, além de uma modificação cultural da sociedade, tão temerosa em relação à utilização de inovações tecnológicas para o refinamento das técnicas construtivas, faz-se necessário que haja uma remodelagem da gestão atual.

Neste contexto, as empresas vêm aprimorando seus métodos não somente produtivos, mas também de seleção profissional, visto que se espera tão logo que a Construção Civil possa incorporar a prática da Lean Construction - ou Construção Enxuta - definitivamente ao seu 
sistema, a fim de evitar desperdícios e propiciar o melhor e mais vantajoso produto ao cliente, sem que fatores como produtividade e qualidade sejam negativamente afetados.

Diante disto, várias são as organizações que tem buscado parcerias com os centros de formação de recursos humanos. Isso ocorre com o intuito de aperfeiçoar a formação de futuros trabalhadores na área de atuação da empresa, visando, assim, oferecer profissionais com melhor grau de instrução e cientes da importância da incorporação de inovações ao mercado da construção.

Almejando contribuir para a melhoria da ciência, através do incentivo ao aumento de invenções que podem vir a se tornar inovações no mercado, assim como para a resolução dos mais diversos entraves encontrados na engenharia, o Programa PFRH surgiu como incentivador à pesquisa e descobertas científicas realizadas nas mais diversas áreas do conhecimento, dentre estas, a Engenharia Civil.

Dessa forma, o presente trabalho busca apresentar, mediante estudo exploratório, as características do Programa Petrobras de Formação de Recursos Humanos (PFRH) no IFRN do campus de Mossoró, fazendo uma abordagem sobre a relevância de suas contribuições para o avanço da ciência e crescimento dos futuros profissionais da instituição junto ao programa, bem como a influência deste ensino como intermediador da ligação entre a instituição e o mercado de trabalho.

\section{REFERENCIAL TEÓRICO}

\subsection{Definição características do programa PFRH}

O Programa de Formação de Recursos Humanos (PFRH) é uma ação da Petrobras que, em parceria com instituições de ensino, fomenta bolsas de iniciação científica para os alunos de diversos níveis de ensino, com o objetivo de proporcionar a formação de recursos humanos (IFRN, 2015).

No estado do Rio Grande do Norte, somente duas instituições participam do programa. São elas: Instituto Federal de Educação, Ciência e Tecnologia (IFRN) e Universidade Federal do Rio Grande do Norte (UFRN). Nessas, para alcançar seus objetivos, o PFRH oferece bolsas de estudos para alunos de níveis técnicos e superiores, coordenadores e pesquisadores visitantes do setor de Petróleo, Gás Natural, Energia e Bicombustível, além de investir em melhorias nas condições de ensino e infraestruturas das instituições parceiras (PFRH, 2015).

Conforme o IFRN (2015), o PFRH trata-se de um programa institucional vinculado à Pró-reitoria de Pesquisa e Inovação e de Extensão, e que tem como objetivo principal o de ampliar e fortalecer a formação de recursos humanos voltados ao atendimento da demanda por profissionais qualificados na indústria de petróleo, gás, energia e biocombustíveis. Aliado a isso, o programa também procura reduzir o índice de evasão escolar, aumentar a quantidade de profissionais qualificados nas temáticas do setor 
e, principalmente, melhorar a qualidade dos estudos desenvolvidos nas áreas de pesquisas abordadas.

Neste contexto, o curso de Técnico em Edificações do IFRN participa do PFRH na formação especializada de recursos humanos nas áreas de Engenharia Civil e Arquitetura. O curso foi o último a entrar no programa do campus Mossoró, iniciando a atividade de pesquisa no ano de 2012 e tendo como seu coordenador o professor Diego Ângelo de Araújo Gomes. Como principais contribuições do PFRH na formação dos alunos dessa área, têm-se as seguintes:

I. A melhor formação acadêmica, garantindo também o atendimento à demanda do setor de Petróleo, Gás, Energia e Biocombustíveis;

II. Compartilhamento de conhecimento com os profissionais da educação, através de iniciações científicas, seminários, cursos complementares e discussões;

III. Fornecimento de conhecimento, mediante a iniciação científica e da produção acadêmica, contribuindo para o processo de ensino-aprendizagem do setor de energia integrado à Construção Civil.

Dos campi contemplados pelo programa no IFRN, têm-se os de: Mossoró, Apodi, Caicó, Ipanguaçu, João Câmara, Macau, Natal Central, Natal Zona Norte, Nova Cruz, Parnamirim, Santa Cruz e São Gonçalo do Amarante.

\subsection{Principais atividades desenvolvidas}

Uma vez que a Construção Civil se encontra em crescimento, essa sua expansão se depara com problemáticas que acarretam soluções dispendiosas, e, na maioria dos casos, inviáveis. A fim de aprimorar o aprendizado acadêmico, complementando e diferenciando a formação dos bolsistas do IFRN do campus Mossoró, o PFRH, através da concessão de bolsas aos alunos do curso Técnico em Edificações, incentiva o desenvolvimento de projetos voltados para diversos segmentos da construção, integrado ao ramo petrolífero, buscando sanar entraves ainda encontrados por ambos os setores, mediante a apresentação de alternativas que possam ser utilizadas na indústria para melhorar os métodos construtivos, minimizar os impactos ambientais, dentre outros.

Para tanto, com o intuito de estimular o pensamento técnico e social dos alunos na investigação por soluções passíveis de aplicação no cotidiano das construtoras, sempre levando em consideração o custo-benefício, são normalmente realizados estudos de caso em que se busca identificar quais os maiores desafios em determinados ramos da construção civil, com o intuito de validar cada modelo de estudo do programa. Neste contexto, as pesquisas e aplicações práticas de extensão são fundamentais, haja vista que possibilitam o contato do aluno com o amplo universo construtivo e operacional.

Junto aos orientadores, os bolsistas desenvolvem um cronograma das atividades que pretendem realizar. Este, por sua vez, é previamente analisado pela Petrobras, devendo abordar a importância do projeto, assim como as etapas que o constitui, observando sempre as áreas de interesse da indústria do Petróleo, Gás, Energia ou Biocombustíveis como alvo de aplicação do 
projeto desenvolvido em integração ao seu curso na instituição.

Os integrantes do curso de Edificações buscam realizar suas pesquisas atentando à utilidade para o setor produtivo, tendo em vista as necessidades das empresas brasileiras do ramo de edificações. Neste sentido, é imprescindível atentar-se para as inovações (principalmente relativas a novos materiais ou tecnologias produtivas), para a preocupação ambiental (cada vez maior no setor), e para a necessidade qualitativa em relação ao tempo de produção (fator substancialmente enfatizado, em virtude da competitividade do mercado).

Para isso, os bolsistas contam com a orientação de seus professores, profissionais da área, para realizarem discussões mais profundas sobre as necessidades do complexo da construção civil.

Contudo, o acompanhamento das atividades realizadas por esses não é realizado somente pelos orientadores, mas também pelo próprio programa, através de relatórios mensais, semestrais e anuais, com resultados parciais da pesquisa, de forma a verificar, de fato, o andamento dos projetos, sendo ao final da regência da bolsa obrigatória a elaboração de um relatório final pelo bolsista, independentemente dos resultados alcançados.

O trabalho intitulado "Proposta de estudo sobre a importância dos impactos ocasionados pelas práticas petrolíferas no Rio Grande do Norte e a necessidade do acompanhamento do comportamento dos solos da região" foi um dos trabalhos desenvolvidos no IFRN do campus Mossoró, durante a vigência de um dos convênios do PFRH na instituição. Ele aborda a crescente conscientização da sociedade no que tange às questões ambientais, relatando que há inúmeras áreas que tendem a gerar direta ou indiretamente uma poluição do solo em alto patamar.

A pesquisa ressalta que a finalidade de se utilizar a engenharia como resolução de problemas visa também resolvê-los mediante técnicas inovadoras que propiciem a aliança entre fatores como sustentabilidade, ambiente construtivo e desenvolvimento econômico, garantindo assim a evolução do país através de seus meios de produção sem prejudicar os habitats existentes. Seu objetivo foi propor um estudo referente às áreas afetadas pelas atividades petrolíferas no estado do Rio Grande do Norte, ressaltando os impactos decorrentes destas, e propondo ensaios para a análise do solo dessa região. Para isso, o trabalho demonstra a substancial importância do monitoramento de áreas afetadas pelas atividades agressoras do meio, para que se tenha um acompanhamento com subsídios suficientes para a avaliação da viabilidade de se construir no local (FERNANDES et al. 2014).

Vale salientar também, que embora o programa seja amplamente voltado para o âmbito da pesquisa, ele não somente possibilita o aprimoramento acadêmico, sendo muito mais abrangente ao incorporar a prática profissional ao aprendizado, por intermédio de visitas técnicas (ou de campo), realizadas em projetos cujo cunho também é experimental e não apenas bibliográfico. Através delas os alunos recebem formação especializada, sendo também expostos a problemas reais que os incitam a adquirir mais conhecimento teórico.

O projeto sobre a gestão de Resíduos Sólidos Urbanos, também desenvolvido no campus, por Silva et al. (2013) estuda os grandes volumes de resíduos sólidos produzidos durante todo o processo de construção, demolição, reforma e afins, abordando a integração de programas 
de gerenciamento de resíduos das construtoras, com o intuito de minimização dos impactos ambientais negativos ocasionados. Seu principal objetivo foi relativo à percepção dos alunos do curso de Edificações, em relação à importância da sustentabilidade na Construção Civil.

0 trabalho de pesquisa supracitado definiu as posturas nacional, regional, estadual e municipal que são exercidas na gestão de resíduos sólidos da construção civil, bem como as leis vigentes, demonstrando as conclusões num quadro comparativo, elaborado a partir da aplicação de questionário, a fim de perceber o posicionamento de algumas construtoras da cidade de Mossoró-RN, a respeito da gestão dos resíduos sólidos por estas produzidos. A análise das informações de interesse do projeto mostrou que a existência de normas regulamentadoras sem o enrijecimento da fiscalização governamental sobre as empresas é ineficaz, pois, a responsabilidade pela destinação adequada dos resíduos que produzem é destinada pelas construtoras a empresas terceirizadas e que, como constatado, pouco sabem sobre como esta destinação final é realizada (SILVA et al., 2013).

O "Projeto Bioclimático como Solução para a Economia de Energia Elétrica" também foi temática abordada por bolsistas do programa. 0 projeto abrangeu assuntos referentes à conscientização de usuários, projetistas e construtores, bem como a utilização de elementos construtivos que possibilitam maior e melhor aproveitamento dos recursos energéticos naturais. Os autores do projeto fizeram uso da própria instituição de ensino como ambiente de avaliação, assim como de outras organizações governamentais e privadas.

Essas avaliações buscaram identificar parâmetros entre as modificações positivas enegativas decorrentes das atividades institucionais desenvolvidas ao longo dos anos, observando-se a gradual adoção de elementos tecnológicos em detrimento das medidas sustentáveis, haja vista que o desenvolvimento demasiado das novas tecnologias requer altos dispêndios de energia elétrica, exigindo, dessa forma, o sacrifício dos recursos naturais. Para a climatização das salas de aula do IFRN/Campus Mossoró foi necessária à vedação completa dos espaços, retirando os cobogós, que permitiam ventilação e iluminação natural. 0 projeto desenvolvido apresentou-se como meio para a aproximação entre os pesquisadores e as questões sustentáveis que cercam a construção civil, desenvolvendo a consciência ambiental dos futuros profissionais da área, visto que o mercado está, cada vez mais, à procura daqueles que se preocupam e que buscam atenuar os efeitos da construção exploratória (BEZERRA FILHO et al., 2013).

Dessa forma, percebe-se que, mesmo em estudos distintos, os pesquisadores do programa no campus vêm vivenciando uma relação mais estreita, no que remete à degradação ambiental e a sustentabilidade no setor construtivo, uma vez que pesquisadores do PFRH são também agentes importantes no processo de formação de consciência ambiental, enquanto participantes do processo de produção das edificações, dos materiais e dos artefatos produzidos para amparo das atividades humanas.

Além disso, os bolsistas podem ainda submeter seus projetos em diversos eventos (congressos, feiras, exposições, etc.) relacionados aos setores de atuação do curso, ou eventos diretamente voltados ao PFRH, possibilitando seu desenvolvimento intelectual e propiciando um 
ensino-aprendizagem de excelente qualidade, mediante debates com especialistas na área, que explanam críticas, sugestões e novidades no mercado da construção.

As feiras do PFRH são bons exemplos dessas interações. Estas permitem a integração entre bolsistas, profissionais, orientadores e visitantes de outras instituições, proporciona também, em termos de desenvolvimento cientifico e tecnológico, que todos estes possam se atualizar com diferentes e inovadores conceitos para problemas apresentados pela indústria.

\section{RESULTADOS}

A existência do PRFH no IFRN/Campus Mossoró possibilita o estímulo da capacidade dos alunos de analisar e descrever as informações de caráter essenciais para a realização dos projetos, bem como a habilidade de organização e planejamento, sejam concomitantemente aprimoradas.

O programa traz consigo não só o ganho de experiência profissional curricular, mas mostra também como agregar o conhecimento prático e auxiliar na escolha da área de atuação a se seguir e as possibilidades que ela oferece.

Neste sentido, a constante participação em eventos e exposições organizadas pela Petrobras, em convênio com o IFRN, possui grande relevância para a interação entre orientadores e orientandos, proporcionando um canal comunicativo que permite a divulgação de resultados dos projetos de pesquisa e extensão dos trabalhos desenvolvidos no campus, promovendo também relações com pesquisadores de diversas áreas do conhecimento, assim como os que atuam em linhas de pesquisas semelhantes.

Com o programa foi possível observar melhorias na desenvoltura dos participantes, o que demonstra não somente o desenvolvimento em sua formação acadêmica, mas uma ascensão em seu desempenho enquanto profissional atuante em um mercado altamente competitivo, uma vez que os projetos ajudam a aperfeiçoar a pesquisar, coletar dados e a análise destes, sendo primordial para a experiência do jovem acadêmico.

Além disso, através dele também se busca a integração institucional com troca de experiências entre os alunos, empregando o trabalho em equipe e observando o valor de cada integrante, mediante a motivação para se buscar alcançar os objetivos traçados nas pesquisas, bem como fortalecendo o conceito de responsabilidade pessoal e profissional. Tal fato evidencia a importância do PFRH no que remete ao enriquecimento acadêmico na etapa de formação de um profissional determinado a estar sempre buscando ferramentas de melhoria da capacidade intelectual.

\section{CONSIDERAÇÕES FINAIS}

O presente trabalho apresentou de forma sintetizada as características do Programa Petrobras de Formação de Recursos Humanos e a importância de suas contribuições para a melhoria não só dos futuros profissionais envolvidos com a pesquisa, mas também a visibilidade 
da instituição, que passa a ter um maior reconhecimento pela sociedade, acarretando na facilitação da inserção de seus discentes egressos no mercado de trabalho.

Algumas das atividades realizadas pelos técnicos em Edificações do IFRN/Campus Mossoró, inclusive, trabalharam questões abordadas em ensinos mais avançados, onde apesar de, às vezes, voltadas somente à fundamentação teórica, constituem-se em um padrão preponderante do ensino na instituição, tendo sido o PFRH a ferramenta fundamental no ensino para o desenvolvimento desse perfil profissional diferenciado no mercado do egresso do curso da instituição.

\section{REFERÊNCIAS BIBLIOGRÁFICAS}

ANP. Resolução ANP n 33, 24 de novembro de 2005. Disponível em: http://sites.petrobras.com. $\mathrm{br} / \mathrm{minisite/comunidade \_ cienciatecnologia/portugues/docs/Resolucao-ANP.pdf.} \mathrm{Acesso} \mathrm{em:} 01$ de maio de 2015.

IFRN - Instituto Federal de Educação. Ciência e Tecnologia. Disponível em: <http://portal.ifrn. edu.br/pesquisa/pfrh>. Acesso em: 01 de maio de 2015.

PFRH - Programa Petrobras de Formação de Recursos Humanos. Disponível em: <http://www. petrobras.com.br/pt/quem-somos/carreiras/oportunidades-de-qualificacao/programa-deformacao-de-recursos-humanos/>. Acesso em: 01 de maio de 2015.

FERNANDES, C. N.; FERNANDES, I. N. S. ; LUCAS, L. E. F. ; OLIVEIRA, R. M. S. ; SILVA, W. G. Estudo sobre a importância da avaliação geotécnica de solos do Rio Grande do Norte em decorrência aos impactos ocasionados pelas práticas petrolíferas. In: III Feira de Ciência e Tecnologia do Programa Petrobras de Formação de Recursos Humanos, 2014, Natal, RN. Anais da $3^{\text {a }}$ Feira de Ciência e Tecnologia do PFRH-IFRN. Natal: Editora do IFRN, 2014. v. 3.

SILVA, A. D. N.; NOBERTO, C. C.; LINHARES, I. S.; OLIVEIRA, C. H. M. A.; MAIA, J. E. F.; BARBOSA, K. P. C. Gestão de resíduos sólidos urbanos. In: II Feira de Ciência e Tecnologia do Programa Petrobras de Formação de Recursos Humanos, 2014, Natal, RN. Anais da $2^{\mathrm{a}}$ Feira de Ciência e Tecnologia do PFRH-IFRN. Natal: Editora do IFRN, 2013. v. 2.

BEZERRA FILHO, F. A.; SOUSA, H. R.; FÉ, J. B.; CABRAL, K. F.; SILVA, K. M. P., BARBOSA, K. P. C. $O$ projeto bioclimático como solução para a economia de energia. In: II Feira de Ciência e Tecnologia do Programa Petrobras de Formação de Recursos Humanos, 2014, Natal, RN. Anais da $2^{\text {a }}$ Feira de Ciência e Tecnologia do PFRH-IFRN. Natal: Editora do IFRN, 2013. v. 2. 